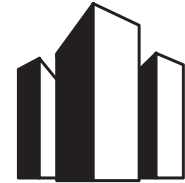

УДК

352.9:331.109:65.012.6

doi: $10.15421 / 15201714$

\section{Особливості механізмів імплементації «чутливості до конфліктів» у проектах публічного сектора}

\author{
Т. В. Маматова
}

Дніпропетровський регіональний інститут державного управління Національної академії держсавного управління при Президентові Украӥни, Дніпро, Україна

У статті розглянуто питання, що пов'язані з визначенням особливостей механізмів імплементації «чутливості до конфліктів» у проектах публічного сектора, які ще не знайшли достатнього опрацювання у фахових виданнях 3 державного управління в Україні. Подано визначення основних пов'язаних категорій предметної сфери «чутливості до конфліктів» за настановами Conflict Sensitivity Consortium: «чутливість до конфліктів», «конфлікт», «аналізування конфлікту», «аналізування чутливості до конфлікту». Встановлено основні положення щодо особливостей механізмів імплементації конфлікт-сенситивного проектного/ програмного менеджменту у контексті забезпечення успішності проектів місцевого розвитку через інтегрування «чутливості до конфліктів» до всіх трьох фаз проектного циклу, за якими реалізується втручання: чутливе до конфліктів планування; чутлива до конфліктів реалізація; чутливі до конфліктів моніторинг та оцінювання. Наведено приклад застосування конфлікт-сенситивного проектного менеджменту у міжнародному проекті EUNPACK «Добрі наміри, змішані результати - чутливе до конфліктів розкриття комплексного підходу СС до механізмів конфліктів і криз», що має на меті розробити рекомендації щодо вдосконалення механізмів реагування СС на кризи за рахунок збільшення їх чутливості до конфліктів і контексту.

Ключові слова: проект місцевого розвитку; конфлікт-сенситивний проектний/програмний менеджмент; проектний цикл; управління проектами

\title{
Features of conflict sensitivity implementation mechanisms' in the public sector projects
}

\author{
T. V. Маматоva \\ Dnipropetrovsk regional institute of public administration of National academy \\ for public administration under the President of Ukraine, Dnipro, Ukraine
}

It has been found in the study that potential conflicts are natural for public sector projects. Among the factors, that predetermine it, one can distinguish the following: the opposite to the processes of making changes; competition of participants during the allocation of project resources; different opportunities to access the project product; insufficient consideration of interested parties' interests; context conflicts; directing the project to resolve the conflict in the territory; unsuccessful selection of the project team. Consequently, the article deals with the issues related to the definition of the peculiarities of the «conflict sensitivity» implementation mechanisms in the public sector projects. This topic has not been studied thoroughly in the specialized publications on public administration in Ukraine. Definitions of main related categories of the «conflict sensitivity» domain based on Conflict Sensitivity Consortium guidelines have been described in the study: «conflict sensitivity», «conflict», «conflict analysis», «conflict sensitivity analysis». The main ideas on the peculiarities of conflict-sensitive project / program management implementation mechanisms in the context of ensuring the success of local development projects by the integration of «conflict sensitivity» into all three phases of the project cycle, under which the intervention is implemented, are as follows: conflict-sensitive planning; conflict-sensitive implementation; conflict-sensitive monitoring

Цитування даної статті: Маматова Т. В. Особливості механізмів імплементації «чутливості до конфліктів» у проектах публічного сектора / Т. В. Маматова // Аспекти публічного управління. - 2017. - Т. 5. - № 5-6(4344). - C. $27-34$

Citation of this article: Маматоva, T. V., 2017. Osoblyvosti mekhanizmiv implementatsiyi «chutlyvosti do konfliktiv» u proektakh publichnoho sektoru [Features of conflict sensitivity implementation mechanisms' in the public sector projects]. Public administration aspects 5, 5-6(43-44), 27-34. doi: 10.15421/15201714 (in Ukrainian).

Peer-reviewed, approved and placed: 16.04 .17 
and evaluation. The example of the conflict-sensitive project management use is: EUNPACK international project «Good intentions, mixed results - A conflict sensitive understanding of the EU comprehensive approach to conflict and crisis mechanisms», which aims to develop recommendations on the improvement of the EU crises response mechanisms by the increase of their sensitivity to conflict and context. As a result, prospects for further research have been defined. As the mechanisms of implementation of the "conflict sensitivity» in public sector projects have been poorly researched in Ukraine and taking into account the significant level of conflict in the environment, where local development projects are implemented, the need for further scientific research in this subject area has been proven. In particular, the scientific substantiation of the mechanisms of Ukrainian local development projects' managers and teams competence improvement has been described in the sphere of conflict-sensitive project / program management's implementation.

Keywords: project of the local development; conflict-sensitive project/programme's management; project cycle; project management

\title{
Особенности механизмов имплементации «чувствительности к конфликтам» В проектах публичного сектора
}

\author{
Т. В. Маматова
}

Днепропетровский региональный институт государственного управления Национальной академии государственного управления при Президенте Украины,, Днепр, Украина

В статье рассмотрены вопросы, которые связаны с определением особенностей механизмов имплементации «чувствительности к конфликтам» в проектах публичного сектора, которые не нашли достаточного освещения в научных публикациях по государственному управлению в Украине. Дано определение основных связанных категорий предметной сферы «чувствительности к конфликтам» в соответствии с руководящими документами Conflict Sensitivity Consortium: «чувствительность к конфликтам», «конфликт», «анализ конфликта», «анализ чувствительности к конфликтам». Представлено основные положения касательно особенностей механизмов имплементации конфликт-сенситивного проектного/программного менеджмента в контексте обеспечения успешности проектов местного развития через интегрирование «чувствительности к конфликтам» во все три фазы проектного цикла, на которых реализуется вмешательство: чувствительное к конфликтам планирование; чувствительная к конфликтам реализация; чувствительные к конфликтам мониторинг и оценивание. Приведено пример применения конфликт-сенситивного проектного менеджмента в международном проекте EUNPACK «Хорошие намерения, смешанные результаты - чувствительное к конфликтам раскрытие комплексного похода ЕС к механизмам конфликтов и кризисов», цель которого - разработка рекомендации по усовершенствованию механизмов реагирования ЕС на кризисы за счет увеличения их чувствительности к конфликтам и контексту.

Ключевые слова: проект местного развития; конфликт-сенситивный проектный/программный менеджмент; проектный цикл; управление проектами

Постановка проблеми. Будь-який проект спрямований на досягнення мети проекту і має забезпечити вирішення проблеми розвитку і задоволення заінтересованих сторін. Ключові учасники, які мають суттєві повноваження i можливості для безпосереднього впливу на реалізацію проекту, завжди є у центрі уваги команди управління проектом, яка має забезпечити найбільш позитивне ставлення і вплив на проект з боку цих ключових учасників, що передбачає врахування їх інтересів у першу чергу. При цьому можуть залишитися без уваги інтереси інших учасників проекту, що призводить до виникнення конфліктів всередині проекту. Оточуюче середовище проекту також $є$ джерелом виникнення конфліктів.

Потенційна конфліктність $є$ природною для проектів публічного сектора. Серед факторів, що іiі зумовлюють, можна виділити такі: супротив процесам здійснення змін; конкуренція учасників під час розподілу ресурсів проекту; різні можливості доступу до користування продуктом проекту; недостатне врахування інтересів заінтересованих сторін; наявна конфліктність контексту (оточення проекту); спрямування проекту на вирішення наявного на території конфлікту; невдалий підбір команди проекту [4].

Це також зумовлено такими особли- 
востями проектів публічного сектора як:

- необхідність зосередження на розбудові співпраці 3 декількома заінтересованими сторонами: працювати, щоб долати бар’єри співпраці;

- значна проникність i чутливість до впливів зовнішнього середовища, що підсилюється із розвитком громадянського суспільства;

- нестабільність оточуючого проект середовища: часті зміни у політиці можуть накладати «тимчасові горизонти» на діяльність за проектом [20].

До цього переліку експерти додають ще одну особливість. Ця особливість за останні роки стала однією 3 ключових - це необхідність розвивати в організаціях, що діють у публічній сфері (особливо для тих, які реалізують проекти місцевого розвитку) «чутливість до конфліктів» (Conflict Sensitivity) [8; 9; $14 ; 16 ; 21-23 ; 25 ; 26]$.

Виявляється, що цей напрям малодосліджений в Україні. Водночас, на наш погляд, $\epsilon$ і надзвичайно актуальним, ураховуючи той рівень конфліктності оточуючого середовища, в якому громадяни нашої країни живуть в останні роки і в якому реалізуються проекти місцевого розвитку.

Аналіз досліджень і публікацій. Спеціальні практично орієнтовані посібники настанови підготовлені у межах діяльності утвореного за ініціативи Великобританії Консорціуму 3 конфлікт-сенситивності (Conflict Sensitivity Consortium) [24] та низки міжнародних ініціатив, програм і проектів [6; $7 ; 9-11 ; 15 ; 16 ; 18 ; 19 ; 21-23 ; 25 ; 26]$. Зазначені нові вимоги до забезпечення процесів імплементації «чутливості до конфліктів» у традиційні процеси управління проектами зумовлюють зростання у світі популярності спеціальних тренінгових програм [12; 13$]$.

У 2015 та 2016 роках під час проведення п'ятого та шостого всеукраїнських е-курсів «Управління проектами місцевого розвитку» на платформі «Спільнота практик місцевого розвитку» [4] за підтримки Швейцарськоукраїнського проекту «Підтримка децентралізації в Україні» DESPRO за рекомендацією організаторів навчання автором було підготовлено навчальні матеріали та відкрито у гілці тематичного форуму «Особливості управління проектами публічного сектора» обговорення за темою «Чутливість до конфліктів як одна 3 ключових особливостей проектів місцевого розвитку». Обговорення виявило, що учасники не мають достатньої інформації за цим напрямом, але відчувають потребу у розвиненні відповідних складових компетентносTi.

Вітчизняні фахові публікації за досліджуваним напрямом більшою мірою спрямовані на вивчення аспектів управління конфліктами та стресами команди проекту. Так, у статті Д. Бедрія [1] у контексті управління людськими ресурсами в наукових проектах визначено терміни «конфлікт» та «стрес», означено джерела конфліктів та їх зміст, розглянуто методи управління конфліктами, дано визначення терміну «стрес» та виділені його види, зазначено важливість приділення уваги управлінню людськими ресурсами для забезпечення ефективного, своєчасного та якісного виконання наукового проекту, запропоновано у науці управління проектами та програмами розвивати напрямок управління конфліктами та стресами команди проекту.

О. Лебедєвою та О. Матвійківим у роботі [2] здійснено дослідження й аналіз конфліктів проектування, які виникають під час колективного (групового) проектування внаслідок різноманітних технічних i соціальних чинників. Авторами запропоновано архітектуру організаційно-технічного забезпечення колективного процесу проектування, у межах якої виявляють та усувають соціальні й технічні конфлікти, а також розроблено і запропоновано модель управління конфліктами.

Під час дослідження природи та вивчення підходів до ідентифікації конфліктів у проектах I. Коржов та 3. Ривак виокремлюють конфлікти, пов'язані з умовами реалізації проекту, що залежать від середовища або оточення проекту. При тому визначають, що до зовнішніх можна віднести політичні та загальноекономічні фактори впливу, ступінь впливу яких на проект може дуже сильно варіюватися. Автори також зазначають важливість усвідомлення наявності конфліктів, що пов'язані 3 відмінностями в рівнях зрілості процесів, функціонуючих у учасників проекту та відмінностями в процедурах управління проектом, а також те, що часто не враховуються (носять неявний характер) і виявляються болючими відмінності в управлінні предметною областю (scope), календарним плануванням 
i ризиками, а також процедури передачі в експлуатацію. Залишаючись неявними, дані конфліктні відносини сильно ускладнюють проектну діяльність. Але якщо відмінності усвідомлені, то знаходження компромісу - питання доброї волі сторін [3].

У науковій розробці [5] авторським колективом розкрито сутність та зміст конфлікту як одного 3 процесів публічної політики, який може мати як конструктивний, так і деструктивний характер, визначено основні механізми конфліктів, здійснено їх класифікацію, проаналізовано особливості взаємовідносин інститутів публічної політики та громадянського суспільства.

Таким чином, маємо констатувати, що питання визначення особливостей механізмів імплементації «чутливості до конфліктів» у проектах публічного сектора ще не знайшли достатнього опрацювання у фахових виданнях 3 державного управління в Україні. 3 огляду на це, метою статті є висвітлення визначень основних категорій предметної сфери «чутливості до конфліктів», методологічних положень щодо особливостей механізмів імплементації даного підходу у контексті забезпечення успішності проектів місцевого розвитку, а також навести приклад застосування конфлікт-сенситивного проектного менеджменту у міжнародних проектах.

Виклад основного матеріалу. За визначенням Conflict Sensitivity Consortium «чутли- вість до конфліктів / конфлікт-сенситивність» (Conflict Sensitivity) означає здатність організації: розуміти контекст (середовище та оточення проекту), в якому вона функціонує; розуміти взаємодію (interaction) між втручанням з iii боку (intervention) і контекстом (context); діяти із розумінням цієї взаємодії для того, щоб мінімізувати негативні наслідки і максимізувати позитивні впливи на конфлікт [19].

Наведемо також декілька пов'язаних визначень, які подано у настановах Conflict Sensitivity Consortium [19; 24].

Конфлікт (Conflict) - результат незгоди і дій сторін, що грунтуються на основі сприйнятих, але таких, що не збігаються інтересів і поглядиів (perceived incompatibilities).

Конфлікт насильницький (Violent Conflict) - вирішення розбіжностей через застосування (resorting) психологічної або фізичної сили.

Аналізування конфлікту (Conflict Analysis) - структурований процес аналізування задля кращого розуміння конфлікту (його фон/історія, групи, що залучені, перспективи кожної групи, виявлення причин конфлікту тощо).

Аналізування чутливості до конфлікту (Conflict Sensitivity Analysis) - порівняння інформації за результатами аналізування конфлікту 3 ключовими (проектними) параметрами (хто, що, де, коли, яким чином) та рішеннями (за проектом) для підвищення адаптації чутливості до конфлікту.

На практиці підхід реалізується через

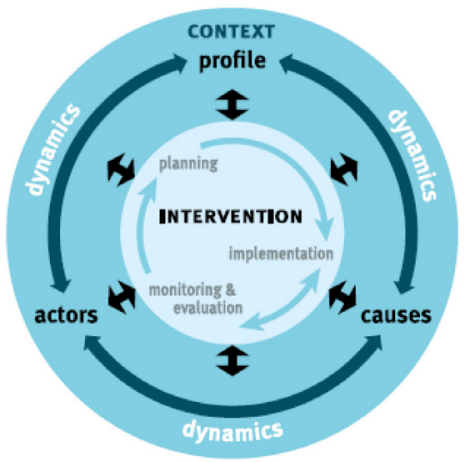

Рис. Модель проектного циклу, до фаз якого має бути інтегровано «чутливість до конфліктів» $[6]^{1}$

1 Переклад категорій, що використані на схемі і не розглядалися раніше у тексті: «dynamics» - динаміка/зміни у середовищі / оточенні проекту; «рrofile» - профіль / унікальність проекту; «causes» - фактори / причини проблеми, на вирішення якої спрямований проект; «actors» - актори / учасники проекту. 
імплементацію процесів «Конфлікт-сенситивного проектного/програмного менеджменту» (Conflict-Sensitive Project/ Programme Management (CSPM) [11] Притому «чутливість до конфліктів» інтегрується до усіх трьох фаз проектного циклу (project cycle), за якими реалізується втручання (intervention): планування (planning); реалізація (implementation); моніторинг та оцінювання (monitoring and evaluation) (рис.).

Розглянемо особливості механізмів імплементації «чутливості до конфліктів» на трьох фазах проектного циклу.

«Чутливе до конфлікту планування» (conflict-sensitive planning) здійснюється в контексті залучення всіх точок вздовж спектра конфліктів (від структурного насильства до насильницьких конфліктів), незалежно від того чи проект або програма спрямовані на гуманітарну допомогу, на розбудову миру, чи на розвиток; чи намір полягає у вирішенні конфлікту безпосередньо, чи в тому, щоб просто уникнути побічного посилення напруженості. «Конфлікт-чутливе планування» будується на елементах, які виявлені в ході аналізування конфліктів у співставленні із особливостями профілю, причин виникнення проблеми, учасників проекту і його динаміки, i, фактично, «вміщує» планування проекту у це аналізування.

«Чутлива до конфлікту реалізація» (conflict-sensitive implementation) додатково включає в себе ретельне вивчення контексту діяльності через регулярне оновлення аналізування конфлікту, пов'язуючи це розуміння контексту з метою і процесами реалізації проекту, і відповідним коригуванням цих процесів. Механізм імплементації «чутливої до конфлікту реалізації» проекту заснований на аналізуванні конфліктів і плануванні процесів проекту. Ключовими елементами цієї фази є:

- чутливе управління процесом реалізації (роботами, персоналом, інформаційними мережами, фінансами тощо);

- здійснення регулярного моніторингу контексту діяльності та взаємодії між втручанням і контекстом, використовуючи індикатори, що визначені під час аналізування конфлікту і фази планування;

- налаштування проекту у світлі нової інформації, отриманої за допомогою моніторингу, із приділенням особливої уваги цілям і процесам реалізації.
«Чутливий до конфлікту моніторинг» (conflict-sensitive monitoring) надає учасникам проекту можливість отримати детальне уявлення про контекст, втручання і взаємодію між ними. Він додає механізм збирання додаткових даних про учасників, профіль, причини та динаміку конфлікту до традиційних моніторингових процесів i робіт 3 метою отримання інформації щодо необхідності здійснення коригування та змін у роботах проекту або програми. Таким чином, конфлікт-чутливий моніторинг допомагає забезпечити настільки позитивний вплив втручання на динаміку конфлікту, наскільки це $є$ можливим.

Результати такого оцінювання можуть бути використані для регулювання наступних етапів реалізації проекту та надати уроки для майбутніх проектів та програм. Іншими словами, у той час як традиційний моніторинг та оцінювання орієнтовані насамперед на оцінювання передбачуваних і фактичних продуктів/ результатів даного проекту, «чутливі до конфлікту моніторинг і оцінювання» додатково вимагають: розуміння контексту і того, як він змінюється з часом; вимірювання взаємодії між проектом і контекстом.

Зазначені нові вимоги до забезпечення процесів імплементації «чутливості до конфліктів» у традиційні процеси управління проектами зумовлюють реалізацію окремих масштабних проектів, наприклад EUNPACK: Good intentions, mixed results - A conflict sensitive unpacking of the EU comprehensive approach to conflict and crisis mechanisms (Добрі наміри, змішані результати - Чутливе до конфліктів розкриття комплексного підходу ЄС до механізмів конфліктів і криз), що стартував 1 квітня 2016 р. та буде тривати до 31 березня 2019 р. за координації NORSK UTENRIKSPOLITISK INSTITUTT (Норвегія) [17].

Проект EUNPACK, бюджет якого складає близько 2,5 млн. EUR, спрямований на «розпаковування» (ретельне аналізування та адаптацію) механізмів кризового реагування $\mathrm{CC} 3$ метою підвищення їх чутливості до конфліктів та ефективності. За допомогою комбінування підходу розгляду перспектив «знизу догори» 3 інституційним підходом EUNPACK має збільшити розуміння того, яким чином функціонують антикризові заходи $\mathrm{CC} \mathrm{i} \mathrm{як}$ сприймаються на місцях у кризових районах. 
Проект також передбачає вивчення всього циклу кризи, від докризового, через кризу і в посткризовій фазі. EUNPACK аналізуватиме два «розриви»у кризового реагування ЄС. По-перше, розрив наміри - реалізація, який належить до: здатності приймати рішення, реагувати «одноголосно» і розгортати необхідні ресурси; здатності реагування на місцях різними інститутами СС та державами-членами; здатності «акторів»- місцевих і міжнародних - підсилити або нівелювати діяльність СС. По-друге, проект спрямований на розрив між здійсненням політик і підходів $€ С$, тим, як ці політики і підходи приймаються і сприймаються в цільових країнах.

Основна гіпотеза EUNPACK полягає в тому, що ступінь глибини двох «розривів» $\epsilon$ вирішальним фактором для впливу СС із врегулювання криз і тим самим його здатність більш ефективно сприяти вирішенню проблем на місцях. Аналізування «розривів» буде здійснюватись на основі «кейсів», які відображають зміну антикризових заходів СС в трьох концентричних областях, що оточують ЄС: область розширення (Косово, Сербія), область сусідства (Україна, Лівія) і розширеного сусідства (Малі, Ірак, Афганістан).

Учасниками проекту є десять дослідницьких установ 3 десяти країн: Великобританії, Німеччини, Бельгії, Словаччини, Італії, Сербіi, Косово,України, Франції, Сенегалу та Іраку. Від України у EUNPACK бере участь Національний університет «Києво-Могилянська академія». Результати дослідження дозволять розробити рекомендації щодо удосконалення механізмів реагування $С С$ на кризи за рахунок збільшення їх чутливості до конфліктів і контексту.

Висновки. «Чутливість до конфліктів / конфлікт-сенситивність» означає здатність організації: розуміти контекст (середовище та оточення проекту), в якому вона функціонує; розуміти взаємодію між втручанням з іiі боку і контекстом; діяти із розумінням цієї взаємодії для того, щоб мінімізувати негативні наслідки і максимізувати позитивні впливи на конфлікт. Механізм імплементації конфлікт-сенситивного проектного/ програмного менеджменту у контексті забезпечення успішності проектів місцевого розвитку реалізується через інтегрування «чутливості до конфліктів» до усіх трьох фаз проектного циклу, за якими реалізується втручання: чутливе до конфліктів планування; чутлива до конфліктів реалізація; чутливі до конфліктів моніторинг та оцінювання.

Перспективи подальших досліджень. Оскільки механізми імплементації «чутливості до конфліктів» у проектах публічного сектора є малодослідженими в Україні та враховуючи значний рівень конфліктності оточуючого середовища, в якому реалізуються проекти місцевого розвитку, актуалізується потреба подальшого наукового дослідження у цій предметній галузі, зокрема наукове обгрунтування механізмів розвитку компетентності керівників і команд проектів місцевого розвитку в Україні у сфері реалізації конфлікт-сенситивного проектного/програмного менеджменту.

\section{БІБЛІОГРАФІЧНІ ПОСИЛАННЯ}

1. Бедрій Д. І. Управління людськими ресурсами в наукових проектах / Д. І. Бедрій // Управління розвитком складних систем. - 2015. - Вип. 24. - С. 16 - 22. - Режим доступу : http://urss.knuba.edu.ua/files/zbirnyk-24/3.pdf.

2. Лебедєва О. О. Аналіз та вирішення конфліктів проектування засобами організаційно-технічного забезпечення у колективних САПР / Лебедєва О.О., Матвійків О.М., 2008. - Режим доступу : http://vlp.com.ua/files/05_21.pdf.

3. Коржов I. В. Конфлікти в проектах: їх природа та ідентифікація / I. В. Коржов, 3. М. Ривак // Інтегроване стратегічне управління: проблеми адміністрування, економічної безпеки та проектної діяльності : тези доповідей першої міжвузівської науково-практичної конференції, 24-26 квітня 2013 р., Львів / Національний університет «Львівська політехніка». - Львів : Видавництво Львівської політехніки, 2013. - С. 41-42. - Режим доступу : httр:// ena.lp.edu.ua:8080/bitstream/ntb/22404/1/21-Korzhov-41-42.pdf.

4. Спільнота практик місцевого розвитку. - Режим доступу : http://udl.despro.org.ua/.

5. Управління конфліктами у процесах публічної політики: взаємодія держави та громадянського суспільства : наук. розробка / авт. кол. : С. О. Телешун, І. В. Рейтерович, С. В. Ситник та ін. - К. : НАДУ, 2012. - 52 с.

6. Applying conflict sensitivity at project and programme level (Chapter 3) // Conflict-sensitive approaches to development, humanitarian assistance and peace building: tools for peace and conflict impact assessment: Resource Pack. - Access mode : http://www.conflictsensitivity.org/sites/default/files/RP_Chapter3.pdf.

7. Conflict sensitivity and analysis for effective EU external action. - Access mode : https://capacity4dev.ec.europa.eu/ system/files/file/13/05/2015___1842/note_1__conflict_sensitivity_and_analysis_for_effective_eu_external_action.pdf.

8. Conflict-sensitivity in development projects. - Access mode $:$ http://www.transformativ.ch/index.php? $\overline{\mathrm{id}}=34 \& \mathrm{~L}=1$. 
9. Conflict Sensitivity Assessment: «International Assistance in Gaza: Aiding Fragmentation or Unity?». - Access mode : http://www.swisspeace.ch/fileadmin/ user_upload/pdf/KOFF/Analysis__Impact/Gaza_Conflict_Sensitivity_ Assessment.pdf.

10. Conflict-Sensitivity Assessment of EU programmes in Sri Lanka Best practices and recommendations for project partners (Consolidated from Phase I \& II) October 2010. - Access mode : www.saferworld.org.uk/.../ConflictSensitivityAssessmentSriLanka.pdf.

11. Conflict-Sensitive Programme Management CSPM, Integrating conflict sensitivity and prevention of violence into SDC Programms - A handbook for practitioners. - Access mode : http://www.sdc.admin.ch/index.php?navID= 92682\&langID $=1$.

12. Conflict Sensitive Project Management : Durham University Continuing Professional Development course, 3-5 March 2016. - Access mode : https://www.dur.ac.uk/dgsi/pdc/cspm/.

13. Conflict-sensitive project management : IPT Specialisation Course, 22 April - 1 May 2016. - Access mode : http:// www.friedensburg.at/uploads/files/IPT_SC_PM_Outline_DRAFT.pdf.

14. Do No Harm: International Support for Statebuilding. - Access mode : http://www.keepeek.com/Digital-AssetManagement/oecd/development/do-no-harm 9789264046245-en.

15. EU externalaction: Towards conflict sensitivity. - Access mode : http://www.saferworld.org.uk/downloads/pubdocs/ EUConflictSensitivity_Final.pdf.

16. Fact Sheet Conflict Sensitivity : KOFF conflict sensitivity factsheet. - Access mode : http://www.swisspeace.ch/ fileadmin/user_upload/pdf/KOFF/KOFF_Documents/KOFF_Factsheet_Conflictsensitivity.pdf.

17. Good intentions, mixed results - A conflict sensitive unpacking of the EU comprehensive approach to conflict and crisis mechanisms. - 2016. - Access mode : http://cordis.europa.eu/project/rcn/200112_en.html.

18. Haider H. Conflict Sensitivity: Topic Guide. - Birmingham, UK: GSDRC, University of Birmingham, 2014. - 38 p. Access mode : http://www.gsdrc.org/docs/open/gsdrc cs topic guide.pdf.

19. How to guide to conflict sensitivity / The Conflict Sensitivity Consortium. - 2012. - 50 p. - Access mode : http://www. conflictsensitivity.org/content/how-guide.

20. Jałochaa B. Key competences of public sector project managers / Beata Jałochaa, Hans Petter Kraneb, Anandasivakumar Ekambaramc, GraĪyna Prawelska-Skrzypekd // Procedia - Social and Behavioral Science ; 27th IPMA World Congress ; Elsevier Ltd. - 2014. - Vol. 119. - P. 247 - 256. - Access mode : http://www.sciencedirect.com/science/article/pii/ S187704281402120X.

21. Monitoring and evaluating conflict sensitivity: Methodological challenges and practical solutions / Principal Authors : Rachel Goldwyn (CARE International UK), Diana Chigas (CDA Collaborative Learning Projects). - March 2013. - 52 p. - Access mode : http://www.smallarmssurvey.org/fileadmin/docs/M-files/CCRVI/ CCVRI-Monitoring-and-evaluatingconflict-sensitivity-challenges-and-solutions.pdf.

22. Paffenholz T. Aid for Peace: A Guide to Planning and Evaluation for Conflict Zones / Thania Paffenholz, Luc Reychler ; Nomos, Baden Baden, 2007. - Access mode : http://www.conflictsensitivity.org/node/62.

23. Promoting conflict sensitivity amongst donor agencies : Policy Brief / Authors: Tim Midgley, World Vision UK, Howard Mollett, CARE International UK, Ivan Campbell, Saferworld ; The Conflict Sensitivity Consortium. - April 2012. - Access mode : http://9bb63f6dda0f744fa444-9471a7fca5768cc513a2e3c4a260910b .r43.cf3.rackcdn.com files/3613/6854/5968/Donor Conflict Sensitivity Policy Brief.pdf.

24. The Conflict Sensitivity Consortium. - Access mode : http://www.conflict sensitivity.org/content/introduction-0.

25. The Do No Harm project, CDA Collaborative Learning Projects. - Access mode : http://www.cdainc.com/cdawww/ project_profile.php?pid=DNH\&pname $=$ DoNoHarm.

26. The utility and dilemmas of conflict sensitivity / Adam Barbolet, Rachel Goldwyn, Hesta Groenewald and Andrew Sherriff // Berghof Research Center for Constructive Conflict Management. - 2005. - Access mode : http://www.berghoffoundation.org/fileadmin/redaktion/Publications/Handbook/Dialogue Chapters/dialogue4 barbolet etal.pdf.

REFERENCES:

1. Bedriy, D. I., 2015. Upravlinnya lyuds'kymy resursamy v naukovykh proektakh [Human resources management in scientific projects]. Management of complex systems development 24, 16-22. Access: http://urss.knuba.edu.ua/files/ zbirnyk-24/3.pdf. (in Ukrainian).

2. Lebedyeva, O.O., Matviykiv, O.M., 2008. Analiz ta vyrishennya konfliktiv proektuvannya zasobamy orhanizatsiyno-tekhnichnoho zabezpechennya u kolektyvnykh SAPR [Analysis and solution of design conflicts by means of organizational and technical support in collective CAD]. Access: http://vlp.com.ua/files/05_21.pdf. (in Ukrainian).

3. Korzhov, I. V., Ryvak, Z. M., 2013. Konflikty v proektakh: yikh pryroda ta identyfikatsiya [Conflicts in the projects: their nature and identification]. (Intehrovane stratehichne upravlinnya: problemy administruvannya, ekonomichnoyi bezpeky ta proektnoyi diyal'nosti, April 24-26, 2013, L'viv). Lviv Polytechnic Publishing House. 41-42. Access: http:// ena.lp.edu.ua:8080/bitstream/ntb/22404/1/21-Korzhov-41-42.pdf. (in Ukrainian).

4. Spil'nota praktyk mistsevoho rozvytku [Local development Community of practices]. Access: http://udl.despro.org. ua/.

5. Teleshun, S. O., Reyterovych, I. V., Sytnyk, S. V., 2012. Upravlinnya konfliktamy u protsesakh publichnoyi polityky: vzayemodiya derzhavy ta hromadyans'koho suspil'stva : nauk. rozrobka [Conflict Management in Public Policy Processes: Interaction of State and Civil Society: Scientific report. K.: NADU. 52. (in Ukrainian). 
6. Applying conflict sensitivity at project and programme level (Chapter 3). Conflict-sensitive approaches to development, humanitarian assistance and peace building: tools for peace and conflict impact assessment: Resource Pack. Access: http://www.conflictsensitivity.org/sites/default/files/RP Chapter3.pdf.

7. Conflict sensitivity and analysis for effective EU external action. Access: https://capacity4dev.ec.europa.eu/system/ files/file/13/05/2015___1842/note_1___conflict_sensiti vity_and_analysis_for_effective_eu_external_action.pdf.

8. Conflict-sensitivity in development projects. Access: http://www.transformativ.ch/index.php?id $=34 \& \mathrm{~L}=1$.

9. Conflict Sensitivity Assessment: «International Assistance in Gaza: Aiding Fragmentation or Unity?». Access: http://www.swisspeace.ch/fileadmin/ user_upload/pdf/KOFF/Analysis__Impact/Gaza_Conflict_Sensitivity_Assessment.pdf.

10. Conflict-Sensitivity Assessment of EU programmes in Sri Lanka Best practices and recommendations for project partners (Consolidated from Phase I \& II), 2010 (October 2010). Access: www.saferworld.org.uk/.../Conflict-SensitivityAssessmentSriLanka.pdf.

11. Conflict-Sensitive Programme Management CSPM, Integrating conflict sensitivity and prevention of violence into SDC Programms. A handbook for practitioners. Access: http://www.sdc.admin.ch/index.php?navID=92682\&lan$\mathrm{gID}=1$.

12. Conflict Sensitive Project Management, 2016. (Durham University Continuing Professional Development course 3-5 March 2016). Access: https://www.dur.ac.uk/dgsi/pdc/ cspm/.

13. Conflict-sensitive project management, 2016 (IPT Specialisation Course, 22 April - 1 May 2016). Access: http:// www.friedensburg.at/uploads/files/IPT_SC_PM_Outline_DRAFT.pdf.

14. Do No Harm: International Support for Statebuilding.Access: http://www.keepeek.com/Digital-Asset-Management/oecd/development/do-no-harm_9789264046245-en.

15. EU externalaction: Towards conflict sensitivity. Access: http://www.saferworld.org.uk/downloads/pubdocs/EUConflictSensitivity_Final.pdf.

16. Fact Sheet Conflict Sensitivity : KOFF conflict sensitivity factsheet. Access: http://www.swisspeace.ch/fileadmin/ user_upload/pdf/KOFF/KOFF_Documents/KOFF_Factsheet_Conflictsensitivity.pdf.

17. Good intentions, mixed results - A conflict sensitive unpacking of the EU comprehensive approach to conflict and crisis mechanisms, 2016. Access: http://cordis.europa.eu/project/rcn/200112 en.html.

18. Haider, H., 2014. Conflict Sensitivity: Topic Guide. Birmingham, UK: GSDRC, University of Birmingham.

19. How to guide to conflict sensitivity, 2012. The Conflict Sensitivity Consortium. Access: http://www.conflictsensitivity.org/content/how-guide.

20. Jałochaa, B., Kraneb, H. P., Ekambaramc, A., Prawelska-Skrzypekd, G., 2014. Key competences of public sector project managers. Procedia - Social and Behavioral Science. Elsevier Ltd. (27th IPMA World Congress). 119 (2014), 247-256. Access: http://www.sciencedirect.com/science/article/pii/S187704281402120X.

21. Goldwyn, R., Chigas, D., 2013. Monitoring and evaluating conflict sensitivity: Methodological challenges and practical solutions (March 2013). Access: http://www.smallarmssurvey.org/fileadmin/docs/M-files/CCRVI/CCVRIMonitoring-and-evaluating-conflict-sensitivity-challenges-and-solutions.pdf.

22. Midgley, T., Mollett, H., Campbell, I., 2012. Promoting conflict sensitivity amongst donor agencies : Policy Brief. The Conflict Sensitivity Consortium (April 2012). Access: http://9bb63f6dda0f744fa444-9471a7fca5768cc513a2e3c4a260910b.r43.cf3.rackcdn.com/files/361 3/6854/5968/Donor_Conflict_Sensitivity_Policy_Brief.pdf.

23. Paffenholz, T., 2014. Conflict Sensitivity - 20 years of practice: A Critical Reflection. Access: http://www.inclusivepeace.org/sites/default/files/IPTI-Swisspeace-Conflict-sensitivity.pdf.

24. Paffenholz, T., Reychler, L., 2007. Aid for Peace: A Guide to Planning and Evaluation for Conflict Zones. Nomos, Baden Baden. Access: http://www.conflictsensitivity.org/node/62.

25. The Conflict Sensitivity Consortium. Access: http://www.conflict sensitivity.org/content/introduction-0.

26. The Do No Harm project (CDA Collaborative Learning Projects). Access: http://www.cdainc.com/cdawww/project_profile.php?pid $=$ DNH\&pname $=$ DoNoHarm.

27. Barbolet, A., Goldwyn, R., Groenewald, H., Sherriff, A., 2005. The utility and dilemmas of conflict sensitivity. Berghof Research Center for Constructive Conflict Management. Access: http://www.berghof-foundation.org/filead$\mathrm{min} /$ redaktion/Publications/Handbook/Dialogue_Chapte rs/dialogue4_barbolet_etal.pdf.

Малатова Тетяна Валерївна - доктор наук з державного управління, професор Дніпропетровський регіональний інститут державного управління Національної акаделії державного управління при Президентові України

Адреса: 49044, Дніпро, вул. Гоголя, 29

E-mail: tatyana.mamatova@gmail.com

Masamova Tetiana $\boldsymbol{V}$. - doctor of public administration, Full Prof.

Dnepropetrovsk regional institute of public administration, the National academy of public administration, office of the President of Ukraine

Address: 29, Gogol Str., Dnipro, 49044, Ukraine

Address: tatyana.mamatova@gmail.com 